\title{
CONSIDERAÇÕES SOBRE O PROCESSO DE CICATRIZAÇÃO EM FERIDAS DERMAIS EM EQUINOS
}

Denis Steiner ${ }^{1}$, André Giarola Boscarato ${ }^{2}$, Carla Faria Orlandini ${ }^{3}$, Giovanna Fernanda Jardim ${ }^{4}$, Luiz Romulo Alberton ${ }^{5}$

1. Médico Veterinário, Mestre em Ciência Animal pela Universidade Paranaense - Unipar, Umuarama - Brasil

2. Médico Veterinário, Docente do curso de Medicina Veterinária da

Universidade Paranaense - Unipar, Doutorando do Programa em Ciência Animal com Ênfase em produtos bioativos da UNIPAR, Umuarama - Brasil e-mail: andreboscarato@prof.unipar.br

3. Médica Veterinária, docente do Instituto Federal Goiano, Urutaí, Brasil.

4. Acadêmica de Medicina Veterinária na Universidade Paranaense - Unipar, Umuarama - Brasil

5. Docente do Programa de pós-graduação em Ciência Animal com ênfase em produtos bioativos pela Universidade Paranaense - Unipar, Umuarama Brasil.

Recebido em: 06/04/2019 - Aprovado em: 10/06/2019 - Publicado em: 30/06/2019 DOI: 10.18677/EnciBio_2019A39

\begin{abstract}
RESUMO
Feridas cutâneas lacerantes frequentemente são observadas na espécie equina, onde a perda de massa tecidual e contaminação impossibilitam o fechamento primário, necessitando, portanto, do reparo tecidual por segunda intenção, que por sua vez pode levar a um período longo de convalescência e oneroso, aliado ainda a um potencial de formação de cicatrizes não cosméticas, especialmente em feridas profundas distais nos membros. Características singulares do processo cicatricial na espécie e a aplicação inadvertida de curativos podem contribuir para este quadro. Avanços na compreensão do processo reparativo foram recentemente obtidos, embora muitos aspectos ainda sejam controversos. Objetiva-se, portanto, fazer uma revisão das importantes considerações envolvidas, visando uma maior compreensão dos fatores envolvidos na cicatrização e opções terapêuticas deste processo nesta espécie.
\end{abstract}

PALAVRAS-CHAVE: curativos; inflamação; tecido de granulação exuberante.

\section{CONSIDERATIONS IN WOUND DERMAL HEALING IN EQUINE: REVIEW}

\section{ABSTRACT}

Deep dermal wounds often are observed in equines, where the tissue loss and contamination preclude the primary closure, requering tissue repear for second 
intencion, which in turn may lead to a long convalalescense and expensive, even combined with potential to form non-cosmetic scar, especially in deep and low limbs. Unique features of the species and the inadvertent application to dressing may contribute for this. Advances in the understanding to repair process were obtained, althoug several aspects are still controversial. The aim the review the most important considerations involver to repair tissue process and heal to this process in the species.

KEYWORDS: dressing, inflammation, proud flesh.

\section{INTRODUÇÃO}

As dermatopatias dos equinos, apesar de possuírem bom prognóstico na maioria dos casos, podem trazer alterações estéticas e morfofuncionais, além de perdas econômicas com custos relacionados aos tratamentos, comprometimento de carreiras esportivas e desvalorização dos animais (ASSIS-BRASIL, 2015). As feridas de origem traumática são as lesões mais prevalentes nos equinos, distinguindo-se daquelas em outras espécies devido a características únicas, incluindo taxas de cicatrização diferentes entre as raças (PESSOA et al., 2014), localização das feridas e a grande propensão à formação de tecido de granulação exuberante durante o processo de reparo (PROVOST, 2012). Diversos estudos apontaram menores taxas de contração, epitelização e formação de granulação excessiva especialmente nas regiões distais dos membros, que uma vez presente retarda a cicatrização por inibição prévia da contração da ferida e subsequente epitelização, com potencial de formação de ulceras na região (MARTINS et al., 2013).

Dois processos divergentes estão envolvidos na resolução das feridas, reparação e regeneração. Durante a regeneração, o tecido destruído é substituído com células do mesmo funcionamento do tipo perdido; isto ocorre em tecidos que têm uma população sustentada de células capazes de sofrer divisão mitótica (osso, epitélio, fígado). Reparação, por outro lado, é uma reação substitutiva por tecido fibrótico concebido para reestabelecer a continuidade dos tecidos, e em última análise, resulta em tecido não-funcional ou cicatricial (RUH et al., 2013).

Aberrações no processo de reparo normal levam a resultados ainda menos desejáveis, incluindo feridas crônicas, fibrose ou deformidades flexurais. Os dois primeiros destes problemas surgem frequentemente na espécie equina e podem exercer um impacto financeiro significativo como resultado de dispendiosos e onerosos cuidados subsequentes (PROVOST, 2012).

Eficiência e rapidez na cicatrização são objetivos primordiais nos diferentes tratamentos de ferida de equinos, evitando-se desta forma, o tecido de granulação exuberante e consequente redução de custos (SALES PEREIRA et al., 2012). Granulação exuberante tem sido o tema de diversos estudos com foco em sua fisiopatologia e os outros com o objetivo de impedir o seu desenvolvimento. Devido as características singulares do processo cicatricial em feridas cutâneas na espécie equina, objetiva-se com esta revisão, proporcionar uma maior compreensão dos fatores envolvidos no processo cicatricial de feridas dermais e descrever importantes aspectos observados, levando a uma melhor compreensão deste processo na espécie. 


\section{DESENVOLVIMENTO}

O processo reparativo em feridas dermais em equinos inicia-se no momento em que uma barreira celular é quebrada e segue um padrão de fases sincronizadas incluindo inflamação aguda, a proliferação celular, e, finalmente, a síntese da matriz e remodelação com a formação de tecido cicatricial. Os mecanismos moleculares que regulam este processo não são completamente compreendidos, mas é evidente que as citocinas são mediadores críticos (CANDREVA, 2017). As citocinas são glicoproteínas de sinalização liberadas pela maioria das células nucleadas no corpo, que atuam como mediadores inflamatórios através de receptores específicos da superfície celular estimulando a migração celular, proliferação e síntese (THEORET, 2001; COUTINHO et al., 2009).

Diversos estudos têm investigado recentemente a fisiologia da cicatrização de feridas nos equinos, na expectativa de proporcionar uma base sólida para novas terapias específicas para a espécie (RIBEIRO et al., 2013). A fase inflamatória é essencial para a proteção contra a infecção, bem como para iniciar o processo de reparação. Foi atribuído aos macrófagos um papel essencial na transição entre a inflamação e a reparação, através da liberação de diversos fatores de crescimento e citocinas (MITCHELL et al., 2012).

Tem sido demonstrado experimentalmente que a inflamação na espécie equina é branda, porém prolongada (BUNDGAARD et al., 2016) e que os leucócitos produzem reações menos essenciais para a morte bacteriana. Eles também produzem níveis mais baixos de outros mediadores necessários para reforçar a resposta inflamatória e na ativação dos miofibroblastos na contração da ferida (WILMINK et al., 2003; CÔRTES, 2013).

Paradoxalmente, a inflamação excessiva ou prolongada pode contribuir para a patogênese com reações específicas durante o reparo das feridas, com produção precoce de tecido de granulação, que é chamado de "exuberante" quando este se eleva acima do nível das bordas da pele interferindo na contração da ferida, retardando a cicatrização (VIANA et al., 2014).

Apesar do influxo de polimorfonucleares (PMN) em cavalos ser mais lento do que a observada em pôneis, estudos demonstram que o total de PMN permaneceu superior em cavalos, mais do que em pôneis durante um longo período de tempo, resultando em inflamação crônica. Supõe-se que o desequilíbrio dos mediadores liberados por polimorfonucleares incluindo TNF- $\alpha$ (fator de necrose tumoral alfa), IL1, IL-6 (interleucina 1 e 6) e TGF- $\beta$-1 (fator de crescimento transformador beta 1) contribuam para a formação de tecido de granulação exuberante. TGF- $\beta 1$ aumenta a migração e a proliferação de fibroblastos e a produção de colágeno subsequente, reduzindo também a apoptose (ALMEIDA, 2017).

\section{Fibroplasia e formação de tecido de granulação exuberante}

Produzido em resposta à baixa tensão de oxigênio tecidual (SORENSEN et al. 2014), o tecido de granulação é estabelecido dentro de 3 a 5 dias, sendo formado a partir da proliferação capilar e de fibroblastos, o que o torna friável, porém resistente à infecção (WINKLER, 2015). O tecido de granulação exuberante é considerado como um importante fator no retardo da cicatrização de feridas por segunda intenção. As proteínas inflamatórias como TGF- $\beta$ desempenham papel importante neste processo (HOLLIS, 2014). Sua formação pode estar ligada à uma ineficiente e prolongada fase inflamatória, levando a condução de uma excessiva fase 
proliferativa mantida pelos fibroblastos em dificuldades de se diferenciarem em miofibroblastos (SANTOS et al., 2014).

Outros fatores foram alvo de estudos e apontam como uma resposta inflamatória específica ineficiente, desbalanceamento de colágeno na hemostase, oclusão microvascular e apoptose celular inapropriada (DIAS; OLIVEIRA, 2012).Um processo de epitelização precoce, requer um tecido de granulação saudável para ocorrer a migração dos queratinócitos, e este é impedido por um processo de inflamação crônica, assim como a contração (WILMINK, 2008; BUDGAARD et al., 2016).

O tecido de granulação exuberante deve ser controlado, uma vez quando se projeta acima das bordas da pele adjacente as feridas. Pode ser feito extirpando a projeção com lâmina de bisturi. Embora este processo seja cruento, a hemorragia geralmente é estancada com a compressão conferida pela confecção de pensos. É ainda, aconselhada a utilização de torniquetes proximais as feridas, conferindo menor sangramento e com isso, melhor visualização do sítio cirúrgico (CARVALHO, 2013).

Para feridas que necessitam ser enfaixadas além do desenvolvimento da granulação inicial, ou quando a exérese da granulação é indesejável, o uso de corticoesteróides tópicos ou um curativo de silicone não aderente, se mostraram bem sucedidos na diminuição da formação das taxas de granulação exuberante (THEORET, 2001; MEDEIROS et al., 2018).

Técnicas de fechamento tardio e o emprego de enxertos de pele são fortemente recomendados em todas grandes feridas, reduzindo assim a área, a inflamação associada e eliminar o problema da granulação exuberante (PROVOST, 2012). O emprego de enxerto cutâneo autólogo, mostra-se excelente alternativa para a diminuição do tempo de cicatrização, bem como custos com tratamentos, além de execução relativamente simplificada com o animal em estação (MARTINS et al., 2018).

A terapêutica de feridas em equinos com utilização de fitoterápicos é uma alternativa adjuvante viável, sendo descritos bons resultados com a utilização de extrato de coité (Crescentia cujete) (CAMPOS et al., 2016), papaína (DOS SANTOS CAMPOS et al., 2017; ORLANDINI et al., 2017); óleo de copaíba (LUCAS et al., 2017); barbatimão (Stryfhnodendron barbatiman) (VIANA et al., 2014), entre outros.

\section{Utilização de Fármacos anti-inflamatórios}

Os equinos também produzem níveis menores de outros mediadores necessários para reforçar a resposta inflamatória e para induzir a contração da ferida (SWAIM et al.,1996). Desta forma, o uso de fármacos anti-inflamatórios deve ser limitado, devido ao potencial efeito inibitório sobre a resposta inflamatória que ocorre na fase inicial da ferida, essencial para as fases subsequentes de debridamento e reparo.

Hussni et al. (2010) observaram em seu estudo um período médio maior (49 dias) para o reparo de feridas experimentais em animais tratados com fenilbutazona em dose terapêutica quando comparado ao controle (37 dias). Em comparação à terapia com corticosteroides, ao mesmo tempo em que eles exercem um efeito antiinflamatório e retardam a fibroplasia, os AINEs suprimem a síntese de prostaglandinas, aliviam a dor e reduzem a vasodilatação sem aparentemente, apresentarem efeitos sobre a fibroplasia. Porém, podem reduzir a migração 
leucocitária "in vitro" e interferir na qualidade da cicatrização (HUSSNI et al., 2004; MAY et al., 1987).

\section{Localização das lesões}

Diferenças foram identificadas em relação ao tempo de cicatrização de feridas de acordo com sua localização. Feridas distais em membros (Figura 1A) cicatrizam mais lentamente quando comparadas com feridas em outras regiões corpóreas (Figura 1B) (JACOBS, 1984).

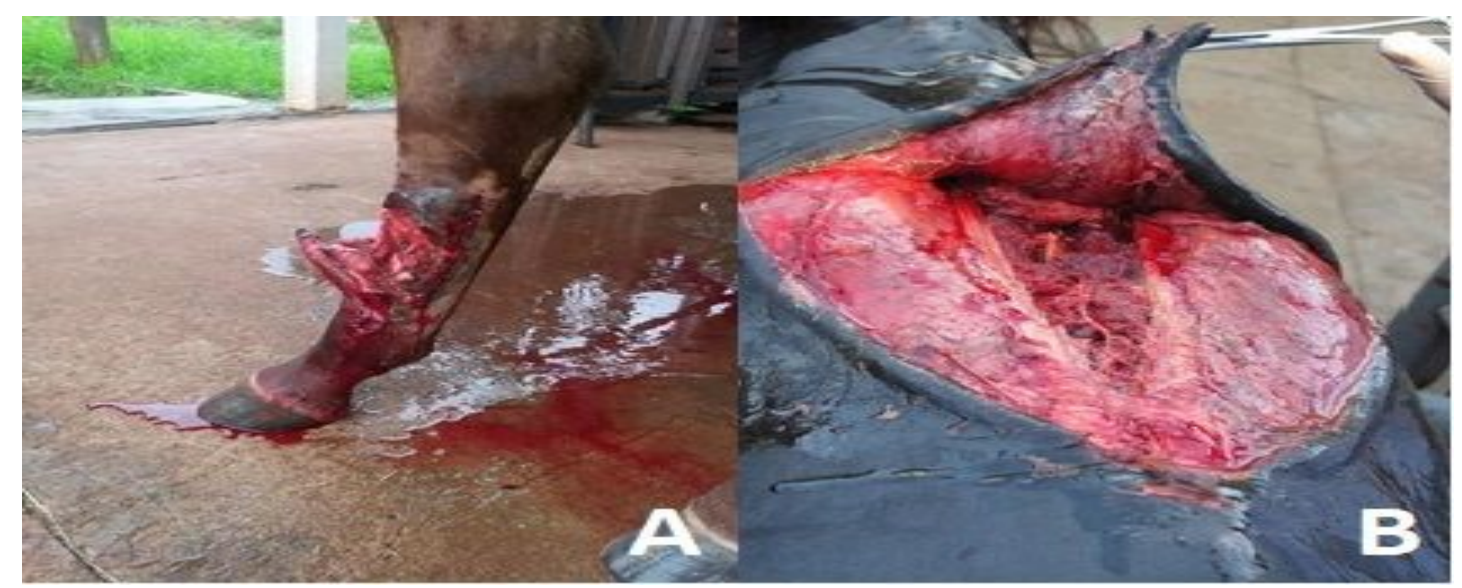

FIGURA 1- Feridas lacerantes em equinos. (A) Região distal de membro pélvico direito; (B) Região dorsal do tórax na região da cernelha.

Fonte: arquivo pessoal dos autores.

Epitelização e contração da ferida ocorrem de forma mais lenta, e contração ocorre em menor escala nos membros quando comparado a outras regiões, com maior propensão a formação de tecido de granulação exuberante, predominantemente em feridas abaixo do carpo e tarso (JACOBS, 1984). As diferenças podem estar relacionadas com 0 aumento das concentrações de citocinas prófibróticas TGF $\beta-1$ em ferimentos distais nos membros e no tecido de granulação, e menores concentrações de TGF $\beta$-3 (Fator de crescimento transformador Beta-3) e citocina anti-fibrótica. Fatores como movimentação excessiva, infecção, também foram atribuídos como responsáveis para um maior período de cicatrização da ferida (SWAIM et al., 1996; THEORET, 2001).

\section{Expansão}

Feridas agudas em cavalos, independentemente da sua localização, se expandem em tamanho nas primeiras duas semanas, devido às forças de tensão dos tecidos adjacentes. Foram observadas taxas de expansão, que aumentaram o leito tecidual em 1,4 a 1,8 vezes o tamanho original (PROVOST, 2012). Harmon et al. (2017), relatam a expansão de feridas experimentalmente induzidas na região do metacarpo e metatarso de equinos, variando entre 3,34 e 5,5\% do tamanho inicial durante os primeiros dez dias. Esta expansão pode ser significativa, contribuindo para o aumento do período de convalescência. 


\section{Confecção de bandagens e curativos}

Conforme sugere Harmon et al. (2017), a aplicação de medicações tópicas em feridas tratadas com bandagens é desnecessária. Na maioria das espécies, a fibroplasia e epitelização são favorecidos por um ambiente úmido na ferida, como a fornecida por diversas modalidades de curativos ou ligaduras, ao passo que na espécie equina, pensos totalmente oclusivos resultam em taxas aumentadas de exsudato na ferida e formação de tecido de granulação exuberante (SWAIM et al., 1996). Uma exceção notável é conseguida com o uso de âmnio, um curativo biológico espécie-específico utilizado em feridas manejadas por segunda intenção no aspecto distal dos membros (TONKS et al., 2003) e em leitos de enxertos (ENGELEN, 2004).

Foi demonstrado que a oclusão microvascular e um processo de apoptose desregulada podem estar envolvidos na acumulação excessiva de matriz extracelular no interior das feridas distais, tal como é o caso no ser humano e o desenvolvimento de quelóides e cicatrizes hipertróficas (CHOI et al., 1996). Isto pode fornecer uma base para o desenvolvimento de terapias específicas para prevenir e tratar fibroplasia excessiva e extensa cicatriz em cavalos (THEORET, 2001).

Não obstante o uso de bandagens (Figura 2) também foi associado com a proliferação de granulação excessiva. Bandagens embora apresentem efeitos benéficos como redução da contaminação, proteção de estruturas primordiais e providenciarem estabilização mecânica, contribuem para um hipóxia focal, estimulando a angiogênese e o acúmulo de exsudato, que por sua vez, promove uma constante fonte de mediadores inflamatórios, ao passo que Berry e Sullins, (2003) em seu relato, preconizam a restrição do uso assim que possível. A hipóxia local também estimula a síntese de TGF- $\beta 1$. A migração de queratinócitos também é diminuída pela presença de granulação exuberante, resultando em menor sinalização a apoptose de fibroblastos e assim, a perpetuação da granulação.

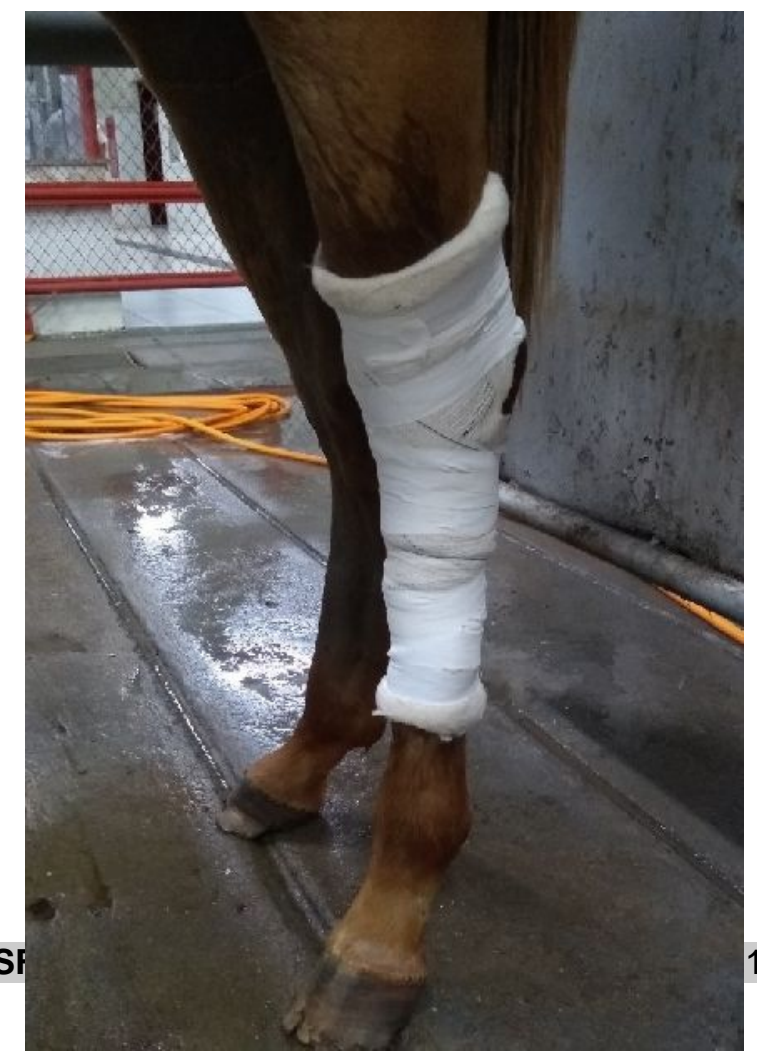


Figura 2: Penso acolchoado oclusivo a base de algodão ortopédico e atadura de crepe, comumente empregado no tratamento de feridas em equinos.

Fonte: arquivo pessoal dos autores.

O desenvolvimento de curativos para cuidados de feridas em medicina humana envolve cifras multibilionárias, e uma diversidade de produtos, muitos dos quais, podem ser satisfatoriamente empregados por veterinários de equinos (PROVOST, 2012). Neste contexto, as bandagens oclusivas tradicionais podem ser substituídas com vantagens por curativos alternativos, visando o controle da formação de granulação exuberante, como as membranas celulósicas bacterianas (OLIVEIRA, 2007), membranas de silicone não aderentes (THEORET, 2001), membranas celulósicas não porosas vegetais (STEINER, 2016).

Mais recentemente, estudos mostraram a versatilidade da utilização de membranas produzidas pela técnica de nanoeletrofiação. Esta técnica possui alto potencial de aplicação na área biomédica, como na produção de curativos para recobrimento de feridas e liberação controlada de fármacos (CHENG et al., 2018). Polímeros nanoeletrofiados a partir de materiais bioativos como a quitosana, mostraram melhores resultados na cicatrização de feridas em animais de laboratório diabéticos (AHMED et al., 2018), possuindo portanto, potencial para utilização como terapia adjuvante em feridas de equinos.

\section{Contração das feridas}

A contração geralmente inicia-se em feridas profundas na segunda semana após a lesão, uma vez que neste período, encontra-se densamente povoada por fibroblastos e pode continuar por várias semanas (FRANZ et al., 2007). Sendo considerado altamente benéfico, pois reduz a área de superfície da ferida original em 40 a 80\% (DI PIETRO; BURNS, 2003). O movimento centrípeto de derme e da epiderme não lesionadas adjacentes, minimizam a área que exige a epitelização (CÔRTES, 2013).

A diferenciação dos fibroblastos em miofibroblastos é considerado pela maioria dos autores como requisito necessário para a contração ocorrer. $\mathrm{O}$ indutor primário na diferenciação de fibroblastos em miofibroblastos parece ser o TGF- $\beta 1$ liberado por macrófagos. Durante este processo, alterações fenotípicas parecem ocorrer, embora ainda, não completamente elucidada, os miofibroblastos parecem fazer conexões com moléculas especializadas entre eles, colágeno e fibronectina da matriz extracelular nos limites das feridas (TRINDADE et al., 2016).

Uma vez que os filamentos de actina estabelecem contatos com miofibroblastos, a força tensil é transmitida através destas conexões para as bordas, causando contração da ferida, geralmente de forma não simétrica, mais sim por eixos de contração, fato que permite um maior alinhamento celular. Este processo cessa ou é completamente inibido quando as bordas se encontram e a tensão dos tecidos circundantes torna-se maior do que a gerada pelos miofibroblastos no leito tecidual, ou quando a população de miofibroblastos se torna reduzida. Ao término 
deste processo estas células desapareceram por apoptose ou retornaram à função fenotípica inicial (EICHLER; CARLSON, 2006; FILHO, 2017).

\section{Infecção}

A infecção também contribui para o atraso na cicatrização de feridas e é a principal razão para deiscência em feridas humanas (DIAS; OLIVEIRA, 2012). Feridas traumáticas contaminadas localizadas nos membros correm riscos maiores de infecção quando comparadas a outras regiões do corpo, uma vez que contaminação fecal e contaminação provenientes do solo são mais frequentemente encontrados em feridas distais (MARTINS et al., 2013).

O desenvolvimento da infecção do ferimento, depende da quantidade e patogenicidade da bactéria e da resistência do hospedeiro. Consequentemente, a dose infectante não precisa ser muito elevada se a bactéria for muito patogênica ou se a resistência do hospedeiro for baixa. Grandes volumes de tecido necrótico também favorecerão a presença de bactérias. Com frequência, a infecção crônica resultará em tecido de granulação frágil e colágeno fraco com padrões desorganizados, causando baixa resistência à tração e reduzida contração do ferimento (LOPES et al, 2016). Estes fatores favorecem a cronicidade da ferida, que tem sido correlacionada também com a presença de biofilmes bacterianos, não sendo determinado ainda, se a cronicidade é causa ou consequência da presença de biofilmes (JORGENSEN et al., 2017).

Visando desenvolver alternativas terapêuticas para feridas infectadas, Edwards-Milewski et al. (2015), propuseram a perfusão regional com sulfato de amicacina, não havendo diferença significativa na cicatrização de feridas experimentalmente induzidas no metacarpo e metatarso em condições assépticas (EDWARDS-MILEWSKI et al., 2015). Em um outro estudo preliminar, Freeland et al. (2016) ao utilizar a perfusão regional com amicacina em feridas inoculadas com Staphylococcus aureus, não observaram redução da carga bacteriana no tecido de granulação de feridas em metacarpo e metatarso. Até novas investigações, os autores sugerem que a redução da carga bacteriana em feridas cutâneas deva ser realizada pelos métodos já estabelecidos, através de terapia tópica, antimicrobianos sistêmicos e debridamento cirúrgico das feridas.

\section{Desbridamento}

Nos períodos iniciais, o desbridamento afeta a cicatrização de forma positiva. O objetivo é reduzir o número de bactérias, debris, sujidades e as taxas de tecidos desvitalizados, que de outra forma, necessitariam serem removidos pela inflamação celular, reduzindo desta forma o período inflamatório.

Em feridas crônicas ou indolentes, onde os fibroblastos apresentam-se senescentes, benefícios foram observados por repetidos desbridamentos. A estimulação cirúrgica promove um acúmulo de plaquetas e assim, reinicia-se o processo de cicatrização (DART et al., 2005). Desbridamento não cirúrgico pode ser obtido através de irrigação e escarificação com gaze. Outra forma de obter-se desbridamento é permitir a ação de proteases contidas no próprio exsudato (CAVALCANTE; LIMA, 2012) mantendo-os em contato com o leito tecidual através de curativos oclusivos (SWAIM et al., 1996), ou através da utilização de cremes enzimáticos à base de colagenases (PROVOST, 2012), papaína (ORLANDINI et al., 2017; STASHAK et al., 2005), bromelina e uréia (CAVALCANTE; LIMA, 2012), com resultados variáveis entre si. 


\section{CONSIDERAÇÕES FINAIS}

Avanços foram obtidos no conhecimento do processo cicatricial em feridas em equinos. Torna-se imperativo, um maior entendimento dos processos envolvidos, visando diminuir a convalescência e os custos relacionados.

\section{REFERÊNCIAS}

AHMED, R.; TARIQ, M.; ALI, I.; ASGHAR, R.; KHANAM, P.N.; et al. Novel electrospun chitosan/polyvinyl alcohol/zinc oxide nanofibrous mats with antibacterial and antioxidant properties for diabetic wound healing. International journal of biological macromolecules, v. 120, p. 385-393, 2018. Disponível em <https://www.sciencedirect.com/science/article/pii/S0141813018319469>. doi: 10.1016/j.ijbiomac.2018.08.057

ALMEIDA, L.A. Membrana de quitosana incorporada com extrato de uva Jacquez para tratamento de feridas cutâneas. Dissertação (Mestrado em Ciência e Engenharia de Materiais) - Universidade Federal de Alfenas, Poços de Caldas, 2017. 93f. Disponível em <https://bdtd.unifal-mg.edu.br:8443/handle/tede/1075>.

ASSIS-BRASIL, N.D.; MARCOLONGO-PEREIRA, C.; STIGGER, A. L.; FISS, L.; SANTOS, B. L.; et al. Equine dermatopathies in southern Brazil: a study of 710 cases. Ciência Rural, v. 45, n. 3, p. 519-524, 2015. Disponível em $<$ http://www.scielo.br/scielo.php?pid=S0103-

84782015000300519\&script=sci_arttext\&tIng=pt>. doi: 10.1590/01038478 cr20140901

BERRY II, D.B.; SULLINS, K.E. Effects of topical application of antimicrobials and bandaging on healing and granulation tissue formation in wounds of the distal aspect of the limbs in horses. American Journal of Veterinary Research, v. 64, n. 1, p. 88-92, $2003 . \quad$ Disponível em $<$ https://avmajournals.avma.org/doi/abs/10.2460/ajvr.2003.64.88>. doi: 10.2460/ajvr.2003.64.88

BUNDGAARD, L.; BENDIXEN, E.; SORENSEN, M.A.; HAR,AM, V.M.; BEYNON, R.J.; et al. A selected reaction monitoring-based analysis of acute phase proteins in interstitial fluids from experimental equine wounds healing by secondary intention. Wound Repair Regen. v. 24, p. 525-532, 2016. Disponível em < https://onlinelibrary.wiley.com/doi/full/10.1111/wrr.12425>. doi: 10.1111/wrr.12425

CAMPOS, G.; JUNIOR, S.; BORGES, L.; RIBEIRO, I.; MARTINEZ, S.; et al. Uso do extrato de coité (crescentia cujete) como fitoterápico em feridas de equinos. Investigação, v. 15, n. 4, p. 95-97, 2016. Disponível em $<$ http://publicacoes.unifran.br/index.php/investigacao/article/view/1186/880>. doi: 10.26843/investigacao.v15i4.1186

CANDREVA, T. Cicatrização de feridas em camundongos FAT-1: envolvimento da via anti-inflamatória colinérgica. Tese (Mestrado em Ciências da Nutrição e do 
Esporte e Metabolismo) - Universidade Estadual de Campinas, Limeira, 2017. Disponível em: <http://repositorio.unicamp.br/jspui/handle/REPOSIP/330649>.

CARVALHO, M.B. Tratamento da pitose cutânea em membros de equinos por meio de perfusão regional intravenosa . Dissertação (Mestrado em Biociência Animal) - Universidade de Cuiabá, Cuiabá, 2013. 102f. Disponível em <http://www.fcav.unesp.br/download/pgtrabs/cir/d/2989.pdf>

CAVALCANTE, B.L.L.; LIMA, U.T.S. Relato de experiência de uma estudante de Enfermagem em um consultório especializado no tratamento de feridas. Journal of nursing health, v.2, n.1, p.94-103, Pelotas, Jan/Jun, 2012. Disponível em: <https://periodicos.ufpel.edu.br/ojs2/index.php/enfermagem/article/view/3447>. doi: 10.15210/jonah.v2i1.3447

CHENG, H.; YANG, X.; CHE, X.; YANG, M.; ZHAI, G.; et al. Biomedical application and controlled drug release of electrospun fibrous materials. Materials Science and Engineering: C, v. 90, p. 750-763, 2018. Disponível em <https://www.sciencedirect.com/science/article/pii/S0928493117322701>. doi: 10.1016/j.msec.2018.05.007

CHOI, B.M.; KWAK, H.J.; JUN, C.D.; PARK, S.D.; KIM, K.Y.; et al. Control of scarring in adult wounds using antisense transforming growth factorb1oligodeoxynucleotides. Immunology Cell Biology, v. 74, p.144-150, 1996. Disponível em <https://onlinelibrary.wiley.com/doi/abs/10.1038/icb.1996.19>. doi: 10.1038/icb.1996.19

CÔRTES, S.M.S. O tratamento de ferida: Um artigo de Revisão. Revista de divulgação Científica Sena Aires, v.2, n.1, p.55-64, Brasília, Jan/Jun, 2013. Disponível em:

http://revistafacesa.senaaires.com.br/index.php/revisa/article/view/46/45>.

COUTINHO, M.A.S.; MUZITANO, M.F.; COSTA, S.S. Flavonoides: Potenciais Agentes Terapêuticos para o Processo Inflamatório. Revista Virtual de Química, v. 1, n.3, p.241-256, Rio de Janeiro, Jun. 2009. Disponível em:<http://rvqsub.sbq.org.br/index.php/rvq/article/view/51 >. doi: 10.5935/1984-6835.20090024

DART, A. J.; DOWLING, B. A.; SMITH, L. C. Topical treatments in equine wound management. The Veterinary Clinics of North America. Equine Practice, Philadelphia, v. 21, n. 1, p. 77-89, 2005. Disponível em: <https://doi.org/10.1016/j.cveq.2004.11.003>. doi: 10.1016/j.cveq.2004.11.003

DI PIETRO, L. A; BURNS, A.L. Wound healing methods and protocols. Nova Jérsei: Humana Press. 2003. Disponível em < https://link.springer.com/book/10.1385\%2F1592593321>. doi: 10.1385/1592593321 
DIAS, R. V. C.; OLIVEIRA, I. V. P. M. Cicatrização de feridas: fases e fatores de influência. Acta Veterinaria Brasilica, v.6, n.4, p.267-271, 2012. Disponível em < https://doi.org/10.21708/avb.2012.6.4.2959>. doi: 10.21708/avb.2012.6.4.2959

DOS SANTOS CAMPOS, S. B.; CAMARGO, A.K.; OLIVEIRA, P.R.P.A.; FELIPE, T.L.; DOS SANTOS, V.D.C.; et al. Uso do extrato de papaína a 5\% na cicatrização de ferida cutânea em equino-relato de caso. Revista Acadêmica: Ciência Animal, v. $15, \quad$ supl. $1, \quad$ p. 2018. <https://periodicos.pucpr.br/index.php/cienciaanimal/article/viewFile/16289/15842>. doi: 10.7213/academica.15.S01.2017.206

EDWARDS-MILEWSKI, M. L.; MORELLO, S.L.; ZHAO, Q.; MATTAN-BELL, C. The

effect of intravenous regional perfusion of the distal limb with amikacin sulfate on wounds healing by second intention in horses. Veterinary Surgery, v. 45, n. 1, p. 125-132, 2016.2 Disponível em <https://onlinelibrary.wiley.com/doi/abs/10.1111/vsu.12435>. doi: 10.1111/vsu.12435 EICHLER, M.J.; CARLSON, M.A. Modeling dermal granulation tissue with the linear fibroblast-populated collagen matrix: A comparison with the round matrix model. Journal Dermatological Science, v. 41, p. 97-108, 2006. Disponível em: <https://www.sciencedirect.com/science/article/pii/S0923181105002628>. doi: 10.1016/j.jdermsci.2005.09.002

ENGELEN, M.; BESCHE, B.; LEFAY, M.P.; HARE, J.; VLAMINCK, K. Effects of ketanserin on hypergranulation tissue formation, infection, and healing of equine lower limb wounds. Canadian Veterinary Journal, v. 45, n. 2, p. 144-149, 2004. Disponível em: < https://www.ncbi.nlm.nih.gov/pmc/articles/PMC548604/>. PMCID: PMC548604

FILHO, S.H.A. Comparativo entre os fios de quitosana e poliglecaprone na reparação intestinal e muscular de coelhos (Oryctolagus cuniculus). Dissertação (Mestrado em Ciência Animal) - Universidade Federal de Goiás, Goiânia, $\quad$ 126p., $2017 . \quad$ Disponível em < https://ppgca.evz.ufg.br/up/67/0/Saulo_Humberto_de_\%C3\%81vila_Filho.pdf>.

FRANZ, M. G.; STEED, D.L.; ROBSON, M.C. Optimizing healing of the acute wound by minimizing complications. Current Problems Surgery, v. 44, p.691, 2007. Disponível em <https://doi.org/ 10.1067/j.cpsurg.2007.07.001>. doi: 10.1067/j.cpsurg.2007.07.001

FREELAND, R.B.; MORELLO, S.L.; DELOMBAERT, M.; RAJAMANICKAM, V. Influence of intravenous regional limb perfusion with amikacin sulfate on Staphylococcus aureus bioburden in distal limb wounds in horses. Veterinary 
surgery, v. 46, n. 5, p. 663-674, 2017. Disponível em <https://onlinelibrary.wiley.com/doi/abs/10.1111/vsu.12638>. doi: 10.1111/vsu.12638

HARMON, C.C.G.; HAWKINS, J.F.; LI, J.; CONNELL, S.; MILLER, M.; et al. Effects of topical application of silver sulfadiazine cream, triple antimicrobial ointment, or hyperosmolar nanoemulsion on wound healing, bacterial load, and exuberant granulation tissue formation in bandaged full-thickness equine skin wounds. American journal of veterinary research, v. 78, n. 5, p. 638-646, 2017.Disponível em <https://avmajournals.avma.org/doi/abs/10.2460/ajvr.78.5.638>. doi: 10.2460/ajvr.78.5.638

HOLLIS, G. Hard-to-heal wounds.In: British Equine Veterinary Association Congress (BEVA), 2014, Birmingham, United Kingdom. Proceeding... Birmingham, United Kingdom: IVIS-International Veterinary Information Service, p.251-252, 2014. Disponível em:

https://researchoutput.csu.edu.au/ws/portalfiles/portal/9708963/30339_Hughes_49th _British_Equine_Veterinary_Association_Congress\%2C_2010\%5B1\%5D.pdf>.

HUSSNI, C. A.; GIANINI, C.G.; ALVES, A.L.G.; NICOLETTI, J.L.M.; THOMASSIAN, A.; et al. Cicatrização cutânea por segunda intenção em equinos tratados com vedaprofeno. Archives of Veterinary Science, v. 9, n. 1, p. 87-97, 2004. Disponível em: <https://revistas.ufpr.br/veterinary/article/viewFile/4051/3282>. doi: 10.5380/avs.v9i1.4051

HUSSNI, C. A.; GROH, T.M.; ALVES, A.L.G.; CROCCI, A.J.; NICOLETTI, J.L.M.; et al. Efeitos da fenilbutazona na cicatrização de feridas cutâneas experimentais em equinos. Brazilian Journal of Veterinary Research and Animal Science, v. 47, n. 4, p. 262-267, 2010. Disponível em: <http://www.revistas.usp.br/bjvras/article/view/26824>. doi: 10.11606/issn.16784456.bjvras.2010.26824

JACOBS, K. A.; LEACH, D.H.; FRETZ, P.B.; TOWNSEND, H.G.G. Comparative aspects of the healing of excisional wounds on the leg and body of horses. Veterinary Surgery, v. 13, n. 2, p. 83-90, 1984. Disponivel em $<$ https://onlinelibrary.wiley.com/doi/abs/10.1111/j.1532-950X.1984.tb00765.x>. doi: 10.1111/j.1532-950X.1984.tb00765.x

JORGENSEN, E.; BAY, L.; BJARNSHOLT, T.; BUNDGAARD, L.; SORENSEN, M.A.; et al. The occurrence of biofilm in an equine experimental wound model of healing by secondary intention. Veterinary microbiology, v. 204, p. 90-95, 2017. Disponivel em <https://www.sciencedirect.com/science/article/pii/S0378113517301943>. doi: 10.1016/j.vetmic.2017.03.011

LOPES, C.R.P.; HONDA, R.R.; MORAIS, A.M.D.; CONCEIÇÃO, L.S.; COURA, L.R.; et al. Lesões Refratárias. Journal of Orofacial Investigation, v. 3, n. 1, p. 70-77, 
2016.

http://revistas.faculdadefacit.edu.br/index.php/JOFl/article/view/164/168>.

LUCAS, F.A.; KANDROTAS, A.L.; NETO, E.N.; SIQUEIRA, C.E.; ANDRÉ, G.S.; et al. Copaiba oil in experimental wound healing in horses. Ciencia Rural, v. 47, n. 4, 2017. Disponível em: <http://www.scielo.br/scielo.php?pid=S010384782017000400601\&script=sci_abstract\&tlng=pt>. doi: 10.1590/0103$8478 \mathrm{cr} 20151292$

MARTINS, E.A.N.; INVERNIZZI, M.S.; CAMPOS, M.G.N.; TEODORO, P.A.; CONTIERI, M.B.; et al. Emprego de membrana de quitosana em feridas cutâneas induzidas experimentalmente em equinos. Ciência Rural, Santa Maria, v. 43, n. 10, p. 1824-1830, 2013. Disponível em < http://www.scielo.br/scielo.php?script=sci_arttext\&pid=S0103-

84782013001000015\&lng=pt\&tlng=pt>. doi: 10.1590/S0103-84782013001000015 MARTINS, W.D.C.; STEINER, D.; NETO, A.B.; BELETTINI, S.T.; ORLANDINI, C.F.; et al. Graft of Small Patch of Partial Thickness in Equine Wound. Acta Scientiae Veterinariae, v. 46, supl. 1, p. 252, 2018. Disponível em <http://www.ufrgs.br/actavet/46-suple-1/CR_252.pdf>. doi: 10.22456/16799216.85126

MAY, S. A.; LEES, P.; HIGGINS, A.J.; SEDGWICK, A.D. Inflammation: a clinical perspective. Veterinary Records, v. 120, n. 120, p. 514-517, 1987. Disponível em <https://www.ncbi.nlm.nih.gov/pubmed/3314098>. doi: 10.1136/vr.120.22.514

ABBAS, A.K.; KUMAR, V.; MITCHELL, R. N. Fundamentos de patologia: Robbins \& Cotran. Rio de Janeiro: Elsevier, cap. 3, p.227, 2012.

MEDEIROS, A.D.C.; SILVA, A.V.D.; LIMA, F.P.; VASCONCELOS, C.V.; MACEDO, L.M.D.B., et al. Efeito do fator XII da coagulação na cicatrização da pele de ratos em uso de corticosteroide. Revista do Colégio Brasileiro de Cirugiões, Rio de Janeiro, v. 29, n. 6, p. 324-329, 2018. Disponível em $<$ http://www.scielo.br/scielo.php?script=sci_arttext\&pid=S010069912002000600004\&lng=pt\&tlng=pt>. doi: 10.1590/S0100-69912002000600004

OLIVEIRA, R.C.S.; VALENTE, P.R.; ABOU-JAMRA, R.C.; ARAÚJO, A.; SALDIVA, P.H.; et al. Biosynthetic cellulose induces the formation of a neoduramater following pre-natal correction of meningomyelocele in fetal sheep. Acta Cirúrgica Brasileira v. 22, p. 174-181, 2007. Disponível em <http://www.scielo.br/scielo.php?pid=s0102$86502007000300004 \&$ script=sci_arttext $>$. doi: 10.1590/S0102-86502007000300004

ORLANDINI, C.F.; BOSCARATO, A.G.; MOURA, R.A.; SAPATEIRO, P.; GAZIM, Z.C.; et al. Utilização de creme de papaína e extrato liofilizado das raízes de salsa (Petroselinum crispum) contra Escherichia coli multirresistente em abscesso em equino. Acta Scientiae Veterinariae, v. 45, p. 1-5, 2017. Disponível em <https://seer.ufrgs.br/ActaScientiaeVeterinariae/article/view/86175/49472>. doi: 10.22456/1679-9216.86175 
PESSOA, A.F.A.; PESSOA, C.R.M.; NETO, E.G.M.; DANTAS, A.F.M.; RIETCORREA, F. Doenças de pele em equídeos no semiárido brasileiro. Pesquisa Veterinária Brasileira, Rio de Janeiro, v. 34, n. 8, p. 743-748, 2014. Disponível em: $<$ http://www.scielo.br/scielo.php?script=sci_arttext\&pid=S0100-

736X2014000800006\&lng=pt\&tIng=pt>. doi:10.1590/S0100-736X2014000800006

PROVOST P.J. Wound healing. In: AUER J.A, STICK J.A. Equine Surgery, 4 ed., p.50-52, Elsevier Saunders: St Louis, 2012.

RIBEIRO, G.; SILVA, M.A.G.; MARTINS, C.B.; BORGES, V.P.; LACERDA NETO, J.C. Associação fitoterápica no tratamento de feridas cutâneas induzidas em equinos. Arquivo Brasileiro de Medicina Veterinária e Zootecnia, Jaboticabal, v. 65, n. 5, p. 1427-1433, 2013. Disponível em: $<$ https://repositorio.unesp.br/bitstream/handle/11449/109507/S0102-

09352013000500022. pdf?sequence=1\&isAllowed=y>. doi: 10.1590/S010209352013000500022

RUH, A.C.; FERNANDES, D.; ARTONI, R.F.; FAVERO, G.M. Inflamação : entre a regeneração e a cicatrização. UEPG Ciências biológicas e da saúde, Ponta Grossa, v. 19, n. 1, p. 11-19, 2013. Disponível em: $<$ https://www.researchgate.net/profile/Roberto_Artoni2/publication/314495445_Infla macao_entre_a_regeneracao_e_a_cicatrizacao/links/596cbe37aca2728ca689d5f6/l nflamacao-entre-a-regeneracao-e-a-cicatrizacao.pdf>. doi: 10.5212

SALES PEREIRA, J. F.; BICALHO, L.; SILVA, D. A. Uso de Própolis associada a outros componentes no tratamento de feridas oncológicas após excisão. Revista Acta Biomedica Brasiliensia, Rio de Janeiro, v. 3, n. 2, p. 15-25, 2012. Disponível em: <http://www.actabiomedica.com.br/index.php/acta/article/view/42/20>. ISSN: 2236-0867

SANTOS, J.A.A.; SOUSA, M.F.A.M.; SILVA, E.L.V.; AGUIAR JÚNIOR, F.C.A. Avaliação histomorfométrica do efeito do extrato aquoso de urucum (norbixina) no processo de cicatrização de feridas cutâneas em ratos. Revista Brasileira de Plantas Medicinais, Botucatu, v. 16, n. 3, supl. 1, p. 637-643, 2014. Disponível em: $<$ http://www.scielo.br/scielo.php?script=sci_arttext\&pid=S1516-

05722014000700001\&lng=pt\&tlng=pt>. doi: $10.1590 / 1983-084 x / 12 \_120$

STEINER, D. Membranas de celulose em feridas e induzidas em equinos. 2016. Dissertação (Mestrado em Ciência Animal) - Universidade Paranaense, Umuarama, 2016. 65f. Disponível em < http://seshat.unipar.br/trabalho/membranas-de-celuloseem-feridas-induzidas-em-equinos/>

STASHAK, T.S.; FARSTVEDT, E.; OTHIC, A. Update on Wound Dressings: Indications and Best Use. Clinical Techniques Equine Practice, v.3, n. 2, p.148163, $2004 . \quad$ Disponível em: 
$<$ https://www.sciencedirect.com/science/article/pii/S1534751604000460?via\%3Dihu b>. Doi: 10.1053/j.ctep.2004.08.006

SWAIM, S.F.; VAUGHN, D.M.; KINCAID, S.A.; MORRISON, N.E.; MURRAY, S.S.; et al. Effect of locally injected medications on healing of pad wounds in dogs. American Journal of Veterinary Research, v. 57, n. 3, p. 394-399, 1996. Disponível em: < https://europepmc.org/abstract/med/8669775>. PMID:8669775

THEORET, C.L.; BARBER, S.M.; MOYANA, T.N.; GORDON, J.R. Expression of Transforming Growth Factor b1, b3, and Basic Fibroblast Growth Factor in FullThickness Skin Wounds of Equine Limbs and Thorax. Veterinary Surgery, v. 30, n. 3, p. 269-277, 2001. Disponível em: <https://onlinelibrary.wiley.com/doi/abs/10.1053/jvet.2001.23341>. doi: https://doi.org/10.1053/jvet.2001.23341

TONKS, A.J.; COOPER, R.A.; JONES, K.P.; BLAIR, S.; PARTON, J.; et al. Honey stimulates inflammatory cytokine production from monocytes. Cytokine v. 21, n. 5, p. 242-247, 2003.2 Disponível em: <https://www.sciencedirect.com/science/article/abs/pii/S1043466603000929?via\%3 Dihub>. doi: https://doi.org/10.1016/S1043-4666(03)00092-9

TRINDADE, L.C.T. Cicatrização cutânea por segunda intenção: influência da aplicação tópica de diferentes concentrações de metronidazol sobre a diferenciação fibroblástica e maturação colágena locais. 2016. Tese (Doutorado em Clínica Cirúrgica) - Universidade Federal do Paraná, Curitiba, 2016. 73 f. Disponível em: <http://hdl.handle.net/1884/49458>.

VIANA, L.F.S.; WENCESLAU, A.A.; COSTA, S.C.L.; FIGUEIREDO, M.A.F.; ANDRADE, F.S.S.D.; et al. Tratamentos complementares para ferida com tecido de granulação exuberante em equino - Relato de caso. Revista Brasileira de Medicina Veterinária, Ilhéus, v. 36, n. 4, p. 417-420, 2014. Disponível em: $<$ http://rbmv.org/index.php/BJVM/article/view/566>.

WINKLER, K.P. Factors that Interfere with Wound Healing.In: The Merck Veterinary Manual, $2015 . \quad$ Disponível em: $<$ http://www.merckvetmanual.com/mvm/emergency_medicine_and_critical_care/wou nd_management/factors_that_interfere_with_wound_healing.httml?qt=GRANULATIO N\%20TISSUE\%2OIN\%20HORSE\&alt=sh>.

WILMINK, J.M.; VEENMAN, J.N.; VAN DEN BOOM, R.; RUTTEN, V.P.M.G.; NIEWOLD, T.A.; et al. Differences in polymorphonucleocyte function and local inflammatory response between horses and ponies. Equine Veterinary Journal, v. 35, n. 6, p. 561-569, 2003. Disponível em: <https://onlinelibrary.wiley.com/doi/abs/10.2746/042516403775467234>. doi: https://doi.org/10.2746/042516403775467234 